FILEVYCH P.V., HRYBEL O.B.

\title{
THE GROWTH OF THE MAXIMAL TERM OF DIRICHLET SERIES
}

Let $\Lambda$ be the class of nonnegative sequences $\left(\lambda_{n}\right)$ increasing to $+\infty, A \in(-\infty,+\infty], L_{A}$ be the class of continuous functions increasing to $+\infty$ on a half-closed interval of the form $\left[A_{0}, A\right)$, and $F(s)=\sum a_{n} e^{s \lambda_{n}}$ be a Dirichlet series such that its maximum term $\mu(\sigma, F)=\max _{n}\left|a_{n}\right| e^{\sigma \lambda_{n}}$ is defined for every $\sigma \in(-\infty, A)$. It is proved that for all functions $\alpha \in L_{+\infty}$ and $\beta \in L_{A}$ the equality

$$
\rho_{\alpha, \beta}^{*}(F)=\max _{\left(\eta_{n}\right) \in \Lambda} \varlimsup_{n \rightarrow \infty} \frac{\alpha\left(\eta_{n}\right)}{\beta\left(\frac{\eta_{n}}{\lambda_{n}}+\frac{1}{\lambda_{n}} \ln \frac{1}{\left|a_{n}\right|}\right)}
$$

holds, where $\rho_{\alpha, \beta}^{*}(F)$ is the generalized $\alpha, \beta$-order of the function $\ln \mu(\sigma, F)$, i.e. $\rho_{\alpha, \beta}^{*}(F)=0$ if the function $\mu(\sigma, F)$ is bounded on $(-\infty, A)$, and $\rho_{\alpha, \beta}^{*}(F)=\varlimsup_{\sigma \uparrow A} \alpha(\ln \mu(\sigma, F)) / \beta(\sigma)$ if the function $\mu(\sigma, F)$ is unbounded on $(-\infty, A)$.

Key words and phrases: Dirichlet series, maximal term, central index, generalized order.

Vasyl Stefanyk Precarpathian National University, 57 Shevchenka str., 76018, Ivano-Frankivsk, Ukraine E-mail: p.v.filevychegmail.com (Filevych P.V.), olha.hrybelegmail.com (Hrybel O.B.)

\section{INTRODUCTION}

We denote by $\mathbb{N}_{0}$ the class of nonnegative integer numbers, and let $\Lambda$ be the class of nonnegative increasing sequences $\lambda=\left(\lambda_{n}\right)_{n \in \mathbb{N}_{0}}$ tending to $+\infty$.

Let $\lambda \in \Lambda$. We consider a Dirichlet series of the form

$$
F(s)=\sum_{n=0}^{\infty} a_{n} e^{s \lambda_{n}}, \quad s=\sigma+i t,
$$

and set

$$
\sigma^{*}(F)=\varlimsup_{n \rightarrow \infty} \frac{1}{\lambda_{n}} \ln \frac{1}{\left|a_{n}\right|}, \quad E(F)=\left\{\sigma \in \mathbb{R}:\left|a_{n}\right| e^{\sigma \lambda_{n}}=o(1), n \rightarrow \infty\right\}
$$

It is easy to see that

$$
\sigma^{*}(F)=\left\{\begin{array}{lll}
-\infty, & \text { if } & E(F)=\varnothing \\
\sup E(F), & \text { if } & E(F) \neq \varnothing
\end{array}\right.
$$

If $\sigma^{*}(F)>-\infty$, then for all $\sigma \in\left(-\infty ; \sigma^{*}(F)\right)$ we define the maximal term and central index of the series $F$ respectively by

$$
\mu(\sigma, F)=\max \left\{\left|a_{n}\right| e^{\sigma \lambda_{n}}: n \in \mathbb{N}_{0}\right\}, \quad v(\sigma, F)=\max \left\{n \in \mathbb{N}_{0}:\left|a_{n}\right| e^{\sigma \lambda_{n}}=\mu(\sigma, F)\right\} .
$$


Let $A \in(-\infty,+\infty]$, and $\alpha: D_{\alpha} \rightarrow \mathbb{R}$ be a real function. We say that $\alpha \in L_{A}$ if two following conditions are fulfilled: (i) the domain $D_{\alpha}$ of $\alpha$ is a half-closed interval of the form $\left[A_{0}, A\right.$ ); (ii) the function $\alpha$ is continuous and increasing to $+\infty$ on $D_{\alpha}$. If $\alpha \in L_{A}$ and $A \leq x \leq+\infty$, then we assume that $\alpha(x)=+\infty$.

For a given $A \in(-\infty,+\infty]$ and $\lambda \in \Lambda$ we denote by $\mathcal{D}_{A}^{*}(\lambda)$ the class of Dirichlet series of the form (1) such that $\sigma^{*}(F) \geq A$ and put $\mathcal{D}_{A}^{*}=\cup_{\lambda \in \Lambda} \mathcal{D}_{A}^{*}(\lambda)$.

Let $\alpha \in L_{+\infty}, \beta \in L_{A}$ and $F \in \mathcal{D}_{A}^{*}$. If the function $\mu(\sigma, F)$ is bounded on $(-\infty, A)$, we set $\rho_{\alpha, \beta}^{*}(F)=0$; if the function $\mu(\sigma, F)$ is unbounded on $(-\infty, A)$, we put

$$
\rho_{\alpha, \beta}^{*}(F)=\varlimsup_{\sigma \uparrow A} \frac{\alpha(\ln \mu(\sigma, F))}{\beta(\sigma)} .
$$

Let $p$ be a positive constant. Under some conditions on functions $\alpha, \beta \in L_{+\infty}$, Sheremeta [1] proved that

$$
\rho_{\alpha, \beta}^{*}(F)=\varlimsup_{n \rightarrow \infty} \frac{\alpha\left(\lambda_{n} / p\right)}{\beta\left(\frac{1}{p}+\frac{1}{\lambda_{n}} \ln \frac{1}{\left|a_{n}\right|}\right)}
$$

for every Dirichlet series $F \in \mathcal{D}_{+\infty}^{*}$ of the form (1). Note that without additional conditions on functions $\alpha, \beta \in L_{+\infty}$ formula (1) is false in general (see e.g. [2,3]).

The following theorem indicates a formula for calculating $\rho_{\alpha, \beta}^{*}(F)$ in the case of arbitrary $A \in(-\infty,+\infty], \alpha \in L_{+\infty}, \beta \in L_{A}$, and $F \in \mathcal{D}_{A}^{*}$.

Theorem 1. Let $A \in(-\infty,+\infty], \alpha \in L_{+\infty}, \beta \in L_{A}$. Then for every Dirichlet series $F \in \mathcal{D}_{A}^{*}$ of the form (1) we have

$$
\rho_{\alpha, \beta}^{*}(F)=\max _{\eta \in \Lambda} \varlimsup_{n \rightarrow \infty} \frac{\alpha\left(\eta_{n}\right)}{\beta\left(\frac{\eta_{n}}{\lambda_{n}}+\frac{1}{\lambda_{n}} \ln \frac{1}{\left|a_{n}\right|}\right)} .
$$

It can easily be shown that Theorem 1 is equivalent to the following theorem.

Theorem 2. Let $A \in(-\infty,+\infty], \alpha \in L_{+\infty}, \beta \in L_{A}$. Then for every Dirichlet series $F \in \mathcal{D}_{A}^{*}$ of the form (1) we have

$$
\rho_{\alpha, \beta}^{*}(F)=\varlimsup_{n \rightarrow \infty} \sup _{x \in D_{\alpha}} \frac{\alpha(x)}{\beta\left(\frac{x}{\lambda_{n}}+\frac{1}{\lambda_{n}} \ln \frac{1}{\left|a_{n}\right|}\right)} .
$$

\section{ProOf of THEOREM 1}

For a sequence $\eta \in \Lambda$ set $k(\eta)=\varlimsup_{n \rightarrow \infty} \frac{\alpha\left(\eta_{n}\right)}{\beta\left(\frac{\eta_{n}}{\lambda_{n}}+\frac{1}{\lambda_{n}} \ln \frac{1}{\mid a_{n}}\right)}$.

Consider a Dirichlet series $F \in \mathcal{D}^{*}$ of the form (1) and prove that $k(\eta) \leq \rho_{\alpha, \beta}^{*}(F)$. If $\rho_{\alpha, \beta}^{*}(F)=+\infty$ it is trivial. Assume that $\rho_{\alpha, \beta}^{*}(F)<+\infty$, and let $\rho>\rho_{\alpha, \beta}^{*}(F)$ be a constant. Then

$$
\ln \mu(\sigma) \leq \alpha^{-1}(\rho \beta(\sigma)), \quad \sigma \in\left[\sigma_{0}, A\right) .
$$

Hence, for every $n \in \mathbb{N}_{0}$ we have $\ln \left|a_{n}\right| \leq \alpha^{-1}(\rho \beta(\sigma))-\lambda_{n} \sigma, \quad \sigma \in\left[\sigma_{0}, A\right)$. Therefore, using the notation $\sigma_{n}=\beta^{-1}\left(\frac{1}{\rho} \alpha\left(\eta_{n}\right)\right)$ for all $n \geq n_{0}$ we obtain

$$
\ln \left|a_{n}\right| \leq \alpha^{-1}\left(\rho \beta\left(\sigma_{n}\right)\right)-\lambda_{n} \sigma_{n}=\eta_{n}-\lambda_{n} \beta^{-1}\left(\frac{1}{\rho} \alpha\left(\eta_{n}\right)\right)
$$


and this can also be written as

$$
\rho \geq \frac{\alpha\left(\eta_{n}\right)}{\beta\left(\frac{\eta_{n}}{\lambda_{n}}+\frac{1}{\lambda_{n}} \ln \frac{1}{\left|a_{n}\right|}\right)}, \quad n \geq n_{0} .
$$

This yields the inequality $k(\eta) \leq \rho$. Since $\rho>\rho_{\alpha, \beta}^{*}(F)$ is an arbitrary, we obtain $k(\eta) \leq \rho_{\alpha, \beta}^{*}(F)$.

It remains to show that there exists a sequence $\eta \in \Lambda$ such that $k(\eta) \geq \rho_{\alpha, \beta}^{*}(F)$. If $\rho_{\alpha, \beta}^{*}(F)=0$, then $k(\eta) \geq \rho_{\alpha, \beta}^{*}(F)$ for every sequence $\eta \in \Lambda$ as is proved above. Let $\rho_{\alpha, \beta}^{*}(F)>0$, and $\left(\rho_{k}\right)_{k \in \mathbb{N}_{0}}$ be a positive sequence that increase to $\rho_{\alpha, \beta}^{*}(F)$. Then it follows from the definition of $\rho_{\alpha, \beta}^{*}(F)$ that there exists a sequence $\left(\sigma_{k}\right)_{k \in \mathbb{N}_{0}}$ increasing to $A$ such that the sequence $\left(v\left(\sigma_{k}, F\right)\right)_{k \in \mathbb{N}_{0}}$ is also increasing and

$$
\alpha\left(\ln \mu\left(\sigma_{k}\right)\right) \geq \rho_{k} \beta\left(\sigma_{k}\right), \quad k \in \mathbb{N}_{0} .
$$

Let $n_{k}=v\left(\sigma_{k}, F\right), k \in \mathbb{N}_{0}$. Consider a sequence $\eta \in \Lambda$ such that $\eta_{n_{k}}=\alpha^{-1}\left(\rho_{k} \beta\left(\sigma_{k}\right)\right), k \geq k_{0}$. Then for every $k \geq k_{0}$ we have

$$
\ln \left|a_{n_{k}}\right|+\lambda_{n_{k}} \beta^{-1}\left(\frac{1}{\rho_{k}} \alpha\left(\eta_{n_{k}}\right)\right)=\ln \left|a_{n_{k}}\right|+\lambda_{n_{k}} \sigma_{k}=\ln \mu\left(\sigma_{k}\right) \geq \alpha^{-1}\left(\rho_{k} \beta\left(\sigma_{k}\right)\right)=\eta_{n_{k}} .
$$

This yields $\rho_{k}<\frac{\alpha\left(\eta_{n_{k}}\right)}{\beta\left(\frac{\eta_{n_{k}}}{\lambda n_{k}}+\frac{1}{n_{n_{k}}} \ln \frac{1}{\mid a_{n_{k}}}\right)}$ for all sufficiently large $k$.

Therefore, $k(\eta) \geq \varlimsup_{k \rightarrow \infty} \rho_{k}=\rho_{\alpha, \beta}^{*}(F)$. Theorem 1 is proved.

\section{REFERENCES}

[1] Sheremeta M.M. Entite Dirichlet series. ISDO, Kyiv, 1993. (in Ukrainian)

[2] Hlova T.Ya., Filevych P.V. Generalized types of the growth of Dirichlet series. Carpathian Math. Publ. 2015, 7 (2), 172-187. doi:10.15330/cmp.7.2.172-187

[3] Hlova T.Ya., Filevych P.V. The growth of entire Dirichlet series in terms of generalized orders. Sb. Math. 2018, 209 (2), 241-257. doi:10.1070/SM8644 (translation of Mat. Sb. 2018, 209 (2), 102-119. doi:10.4213/sm8644 (in Russian))

Received 01.03.2018

Філевич П.В., Грибель О.Б. Зростання максимального илена рядів Аіріхле // Карпатські матем. публ. - 2018. - Т.10, №1. - С. 79-81.

Нехай $\Lambda$ клас невід'ємних зростаючих до $+\infty$ послідовностей $\left(\lambda_{n}\right), A \in(-\infty,+\infty], L_{A}-$ клас неперервних зростаючих до $+\infty$ функцій, заданих на напіввідкритому інтервалі вигляду $\left[A_{0}, A\right)$, а $F(s)=\sum a_{n} e^{s \lambda_{n}}-$ ряд $\Delta$ iрiхле такий, що його максимальний член $\mu(\sigma, F)=$ $\max _{n}\left|a_{n}\right| e^{\sigma \lambda_{n}} \in$ визначеним для всіх $\sigma \in(-\infty, A)$. В роботі доведено, що для довільних функцій $\alpha \in L_{+\infty}$ і $\beta \in L_{A}$ правильна рівність

$$
\rho_{\alpha, \beta}^{*}(F)=\max _{\left(\eta_{n}\right) \in \Lambda} \varlimsup_{n \rightarrow \infty} \frac{\alpha\left(\eta_{n}\right)}{\beta\left(\frac{\eta_{n}}{\lambda_{n}}+\frac{1}{\lambda_{n}} \ln \frac{1}{\left|a_{n}\right|}\right)},
$$

де $\rho_{\alpha, \beta}^{*}(F)$ - узагальнений $\alpha, \beta$-порялок функції $\ln \mu(\sigma, F)$, тобто $\rho_{\alpha, \beta}^{*}(F)=0$, якшо функція $\mu(\sigma, F)$ обмежена на $(-\infty, A)$, i $\rho_{\alpha, \beta}^{*}(F)=\varlimsup_{\sigma \uparrow A} \alpha(\ln \mu(\sigma, F)) / \beta(\sigma)$, якшо функція $\mu(\sigma, F)$ необмежена на $(-\infty, A)$.

Ключові слова і фрази: ряд Аіріхле, максимальний член, центральний індекс, узагальнений порядок. 